\title{
Analysis of Statistical Quality Control by Control Chart to Reduce the Variability of The Product
}

\author{
Ayi Tejaningrum \\ STIE Ekuitas Bandung, Indonesia \\ Email : tejaningrumayi@gmail.com
}

\begin{abstract}
This study aims to analyze how the condition of process quality in the manufacture of "shoulder" as one of the spare parts of railroads in Indonesia. The methodology used is quantitative research with naturalistic alignment, process dictation tool is statistical quality control with $p$ control chart and to analyze correlation between disability effect using Pearson correlation regression with $99 \%$ confidence level. The data analyzed were 66,655 pes produced from July to December 2016. Based on the results of the study, six types of disabilities were found in each stage of the process ie early frozen disability, sand inclusion, slag inclusion, dimensions, air cavity deficiency and Mold Defects. From the control chart on each type of disability indicates that the process is out of control, with data always outside the upper control limit and lower control limits. The data also indicate a very significant relationship and influence between the defects occurring in the initial process of defects in the subsequent process. Thus the management must make efforts to work hard to investigate the cause of uncontrolled process, which is suspected due to engine factors, raw materials and also weak control. Subsequent research is proposed to examine it in more detail so that management can take precautions.
\end{abstract}

Keywords: Statistical Quality Control, Variability of Process, Control Chart

\section{INTRODUCTION}

\section{A. Background Research}

Quality control becomes a very important thing to maintain the quality is within the limits of specifications set by the company. Companies will easily win the competition in the era of globalization when the products delivered are favored by consumers, because it has a quality advantage compared to competitors. One of the state-owned companies in Indonesia, currently producing "shoulder" which is part of the railway tethering facility.

This product is used to meet the needs of railways in Indonesia. There are six stages in the process of making the product that is making the model, making the core box, smelting, sand mold processing, core box installation, dilution, and finishing. During the six stages of the process examination is done four times in order to achieve quality products.

In the production process monitoring must be carried out to keep the product within the specified limits. Monitoring should be done since raw materials enter the final product so that the chance of occurrence of conformity will be easily analyzed. In this product, management specifies six types of suitability that occur: early frozen, sand inclusion defect, defect inclusion slag, defect dimensions, air cavity defects and mold loss defects. From preliminary observations made from July to December 2016 , out of 66,655 pcs produced there were suitability or defects of 4,889 or reached $7.48 \%$ (Sendi: 2017).

The quality of the end product is a contribution of the diversity of qualities at the time of the process, so that each stage in the process that begins from the inspection of the raw material to the final product, is a series of processes that contribute to the diversity of the quality of the final product. The quality of religion is something that consumers do not like because it gives uncertainty about the product specification received (Tejaningrum: 2015). Quality Process Control, is one tool to detect the diversity or variety of products.

\section{THEORETICAL REVIEW}

\section{B. Concept of Quality}

In the manufactured world we will be faced with a variety of data of conformity or disability. Defects or conformities are defined as characteristics that do not meet specifications. Theoretically the concept of quality refers to: Scherkenbach (1991): emphasizes the quality of the value between price and product quality. Deming (1986): quality is meeting the criteria according to consumer requirements. Taguchi (1987) quality is loos to society, meaning is that the resulting product should not be out of consumer taste.

Goetch and Davis (1995): Quality is a dynamic condition related to products, services, people, processes that meet or exceed what was expected. Crosby (1979) Quality is in accordance with the requirements. Feigenbaum (1983) quality is the total composite product and service characteristic of marketing, manufacturing technique, and maintenance where the products and services used will meet customer's expectation. Garvin (1988) mentions eight dimensions of quality, which can be used as a strategic planning and analysis framework: performance, feature, reliability, conformance to specifications, durability, servicebility, esthetic, perceived quality. Crosby (N.Logothetis, 1991: 83) conveys four main limits: Corformance, prevention, Standard performance. Hansen and Mowen (2005: 5) quality is the level of perfection, in this case quality is a relative measure of goodness. 


\section{Quality Process Control}

The production process is the process of transforming input into output. In controlling the process, the control charts were presented which Walter A. Shewhart presented during his work at Bell Labs (now better known as AT \& T Bell Laboratories) in the 1920s. The quality expert of W. Edwars Deming in statistic control process is based on 7 tools: cause diagram, check sheet, pareto chart, run chart and control chart, histogram, scatter diagram.

Heizer and Render (2012) statistical process control (SPC) is a common statistical technique used to ensure a series of processes meet the standards. Basically all processes are affected by variability, and the tools that make it easier to detect variability are the control charts. The main purpose of the use of statistical process control is to provide a statistical signal when there is a cause for special variations, this condition will accelerate the action to exclude the cause of variability.

In the process of quality control statistically Grand (1993) classified it into four:

- Shewhart control chart for measurable quality characteristics. In technical language, it is expressed as a chart for variables, or as a chart of $\mathrm{X}$ and $\mathrm{R}$ (mean and standard sample deviation).

- Shewhart control chart for fractioned rejection. In technical language, it is expressed as a $\mathrm{p}$ chart.

- Shewhart control chart for most characteristics per unit. In technical language, it is expressed as a chart c.

- Part of the sampling theory related to the quality protection obtained from the reception sampling procedure.

Disturbance is a common occurrence in the factory, if the disturbance is a difficulty to meet the specification limits then use the $\mathrm{X}$ and $\mathrm{R}$ control charts. In many cases the inspection of the product is no longer measured from the specified limits of the specification, but rather the two classifications are accepted and rejected.

$$
\mathrm{CL}=\frac{\sum_{n=1}^{n} \bar{p}}{\sum \text { sample }}
$$

$U C L=\overline{\mathrm{p}}+3 \frac{\sqrt{\overline{\mathrm{p}}(1-\overline{\mathrm{p}})}}{\mathrm{ni}}$

$L C L=\overline{\mathrm{p}}-3 \frac{\sqrt{\overline{\mathrm{p}}(1-\overline{\mathrm{p}})}}{\mathrm{ni}}$

$\mathrm{UCL}=$ Upper Control limit: the upper control limit of the process we observe.

LCL $=$ Lower Contral Limit is the lower control boundary of the data we observe and the diameter or average

\section{E. Variability Quality}

A study conducted by Tejaningrum (2013) shows that consistency of quality dimension influences consumer satisfaction. Quality products are not only shown by performance, feature, reliability, servicebility, esthetic, perceived quality must also be demonstrated with consistency from that dimension. Heizer and Render (2012) states that a process works in statistical control when the source of its variation comes from a common or natural source, and this condition can be detected if we are able to uncover the cause of special variations through the control chart. There are two types of variations in the process:

Scientific variation: This variation affects almost all production processes and is commonplace. Scientific variation is a number of sources of variation that occur in a process that is within the control of statistics. Scientific variation acts like a constant system that produces random causes. Although each value is different, as a group, their value forms a pattern that can be described as a distribution. If the distribution is normal, the distribution can be characterized by two parameters namely the average and standard deviation (Heizer and Render: 2012).

\section{Variations continue}

In the process of analyzing variability, uncontrolled or uncontrolled criteria are used if they have the following characteristics (Tejaningrum: 2015): (a) one or more points beyond the control limit (b) 6 or more points have a tendency to rise or fall even if Within the control limit (c) 8 dots or more are kept below or above the tengaah line, even within the control limits. (d) 14 or more points are in a continuous upward and downward trend. When finding any of the four criteria, it indicates that the system is in an uncontrolled condition that makes the product quality inconsistent

\section{RESEARCH METHODOLOGY}

The research is done by natualistik quantitative approach, where the research does not make treatment, the data taken is unique, that is based on the view from the data source not the researcher's view. (Sugiyono: 2008)

To see the relationship between the first process defect condition with the next process will be done by calculating the magnitude of correlation coefficient using Pearson correlation coefficient, because the internal scale data and data follow the normal distribution (Suharyadi Purwanto: (2012).

$$
\rho_{X, Y}=\frac{E(X Y)-E(X) E(Y)}{\sqrt{E\left(X^{2}\right)-E^{2}(X)} \sqrt{E\left(Y^{2}\right)-E^{2}(Y)}}
$$

The hypothesis of this study is suspected that the effect of defects that occur in the upstream process will result in defects in the downstream process. Testing is done in 2 directions, with $99 \%$ confidence level. 


\section{RESULTS AND DISCUSSION}

The following are observational data related to the number of defects occurring in the "Shoulder" making process. The data is collected for 6 months starting from July to December 2016.

Table 1 : Product Defects Data

\begin{tabular}{|c|c|c|c|c|c|c|c|}
\hline \multirow{2}{*}{ No } & \multirow{2}{*}{ Sum } & \multicolumn{6}{|c|}{ Defect } \\
\hline & & $\mathrm{BD}$ & IP & IT & $\mathrm{D}$ & $\mathrm{RU}$ & $\mathrm{RC}$ \\
\hline \multirow{3}{*}{1} & 3789 & 127 & 12 & 14 & 26 & 11 & 91 \\
\hline & 2553 & 126 & 27 & 0 & 23 & 15 & 55 \\
\hline & 2981 & 127 & 11 & 18 & 22 & 17 & 39 \\
\hline \multirow{4}{*}{2} & 7078 & 201 & 20 & 46 & 33 & 6 & 118 \\
\hline & 3819 & 119 & 9 & 10 & 5 & 0 & 121 \\
\hline & 3446 & 120 & 25 & 25 & 24 & 2 & 43 \\
\hline & 1125 & 51 & 0 & 3 & 2 & 4 & 11 \\
\hline \multirow{4}{*}{3} & 1589 & 88 & 0 & 8 & 1 & 8 & 16 \\
\hline & 5086 & 142 & 35 & 30 & 33 & 14 & 120 \\
\hline & 1485 & 84 & 0 & 5 & 3 & 5 & 13 \\
\hline & 1269 & 55 & 0 & 0 & 2 & 0 & 6 \\
\hline \multirow{4}{*}{4} & 2298 & 108 & 2 & 3 & 27 & 5 & 29 \\
\hline & 1194 & 51 & 13 & 7 & 12 & 11 & 11 \\
\hline & 2184 & 108 & 4 & 8 & 29 & 6 & 41 \\
\hline & 1067 & 63 & 5 & 3 & 5 & 0 & 10 \\
\hline \multirow{4}{*}{5} & 1278 & 72 & 8 & 4 & 2 & 1 & 11 \\
\hline & 1287 & 76 & 10 & 0 & 8 & 3 & 4 \\
\hline & 2043 & 114 & 5 & 3 & 0 & 3 & 39 \\
\hline & 5484 & 120 & 39 & 33 & 37 & 44 & 190 \\
\hline \multirow{4}{*}{6} & 2694 & 91 & 39 & 17 & 9 & 18 & 50 \\
\hline & 3225 & 87 & 10 & 7 & 21 & 3 & 107 \\
\hline & 5343 & 95 & 42 & 38 & 24 & 15 & 119 \\
\hline & 4338 & 102 & 33 & 14 & 18 & 16 & 100 \\
\hline
\end{tabular}

Sources : Sendy (2017)

\section{F. Early Frozen Analysis (BD)}

Early frost is related to the conformity shown by the surface of the product, it appears that there is an unfilled portion of the liquid so that the "shoulder" wall is concave or convex as well as the presence of clumps on the product wall (Sendy 2017).

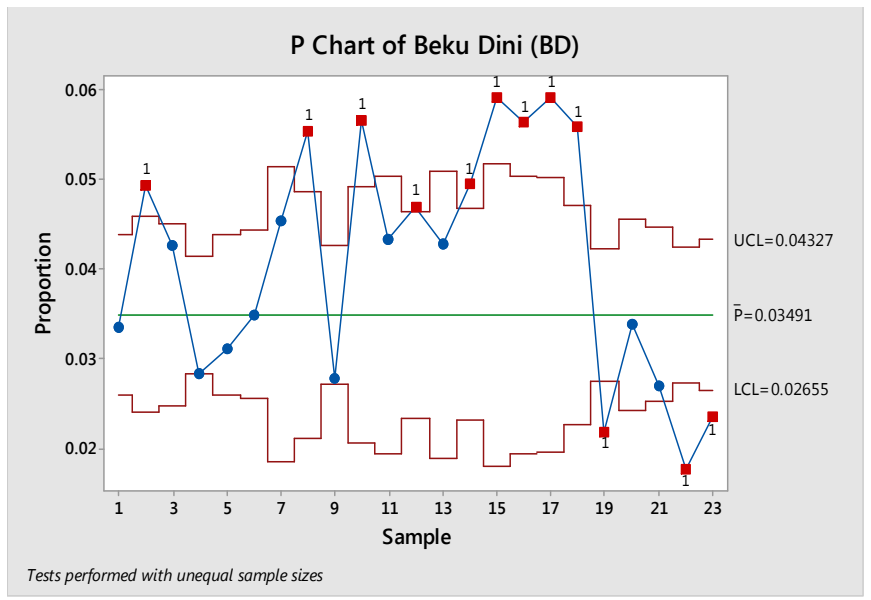

Figure 1: Control chart $p$ with type of early frozen disability (BD)

In Figure 1, it appears that the process is in a different cause system, which is indicated by some data is beyond the control limit ie data number $2.8,10,12,14,16,17,18,19,20,21,22$ and 23 .

\section{G Analysis of Inclusion Sand Mask (IP)}

The inclusiveness of the sand is related to the occurrence of curvature on the surface of the product and the presence of sandy spots. Based on the following observation data is the control chart that occurred.

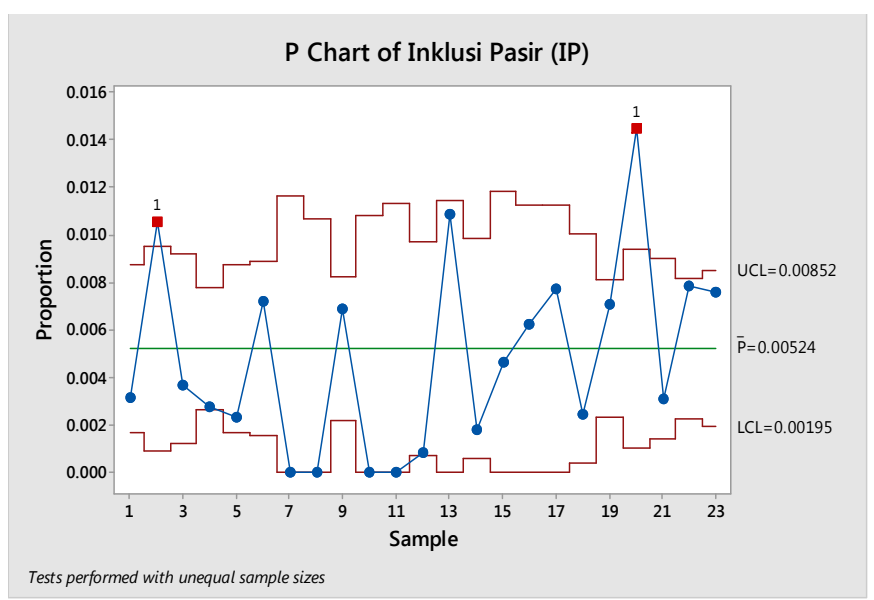

Figure 2: Control chart $p$ on the inclusion of sand

Process conditions show that the process out of control resulting in the diversity of products produced. Out of control appears in samples No. 2 and 20.

\section{H. BI's influence on IP}

What is the relationship between the number of disabilities in the early freezing (BD) on the number of disability inclusion sand (IP 


\section{Correlations BD And IP}

\begin{tabular}{|c|c|c|c|}
\hline & & BD & IP \\
\hline \multirow[t]{2}{*}{ BD } & $\begin{array}{l}\text { Pearson Correlation } \\
\text { Sig. (2-tailed) }\end{array}$ & 1 & $\begin{array}{l}.983^{* *} \\
.000\end{array}$ \\
\hline & $\mathrm{N}$ & 24 & 24 \\
\hline \multirow[t]{2}{*}{ IP } & $\begin{array}{l}\text { Pearson Correlation } \\
\text { Sig. (2-tailed) }\end{array}$ & $\begin{array}{l}.983^{* *} \\
.000\end{array}$ & 1 \\
\hline & $\mathrm{N}$ & 24 & 24 \\
\hline
\end{tabular}

The data show that there is a significant relationship between the number of freeze frosts and the inclusion of Sand of 0.93 , thus the influence of early frozen disability to the inclusion of Sand is equal to $(0.92)^{2}=81 \%$, and another influence of $19 \%$.

\section{Inclusion Slag Analisys (TI)}

The inclusion of slag is a type of conformance that is indicated by a hole on the surface of the product.

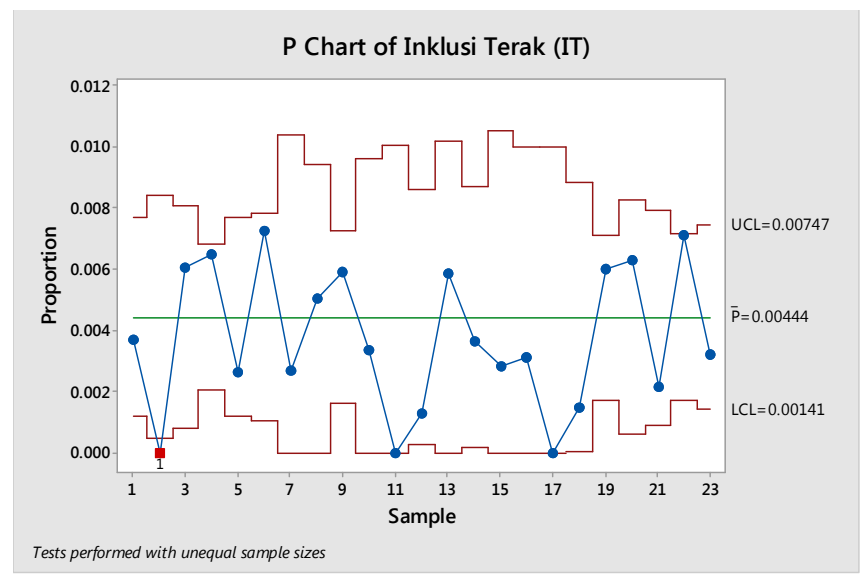

Figure 3: P control chart with the type of Severed Incision Disability

From Figure 3 it appears that the process is in out of control condition, because there is one data outside the lower control limit that is in the second sample.

\section{$J$. The effect of IP on IT}

The magnitude of the disability relationship The sand inclusion with slag inclusion is 0.693 or to the strong correlation between the inclusion of sand inclusion with slag inclusion, of 0.987, while the magnitude of influence is $0.974 \%(0.987) 2$. Thus it can be concluded that the disability inclusion of slag is caused by disability Sand inclusion of $97.4 \%$ while other factors of $2.6 \%$.

\section{Correlations}

\begin{tabular}{|l|c|c|}
\hline & IP & IT \\
\hline IP Pearson Correlation & 1 & $.987^{* *}$ \\
Sig. (2-tailed) & & .000 \\
$\mathrm{~N}$ & 24 & 24 \\
\hline IT Pearson Correlation & $.987^{* *}$ & 1 \\
Sig. (2-tailed) & .000 & \\
$\mathrm{~N}$ & 24 & 24 \\
\hline
\end{tabular}

**. Correlation is significant at the 0.01 level (2-tailed).

\section{K. Dimensional Analisys (D)}

Dimensional defect is a disability related to the difference in the surface diameter of the product compared to the defined standard. Here is the control chart $p$, for dimensional defects

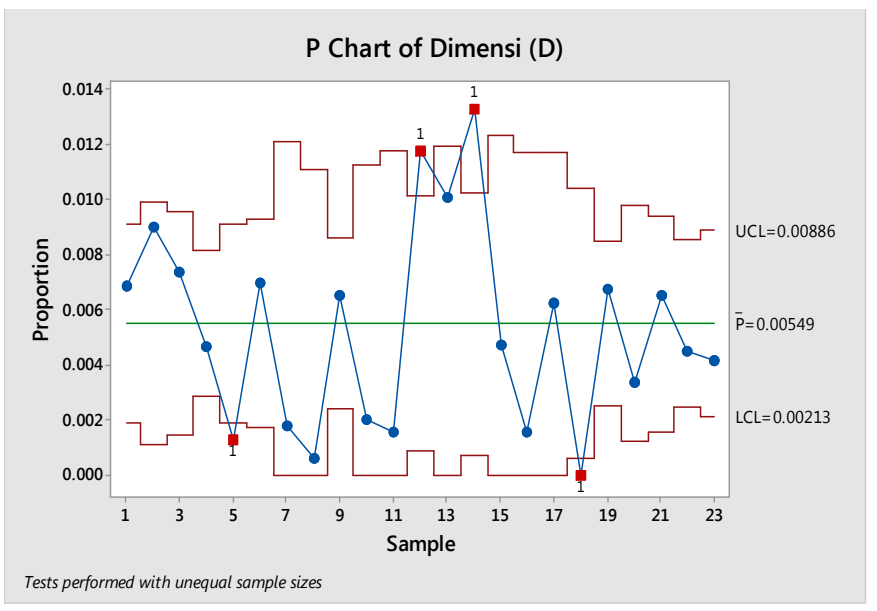

Figure 4: The control chart $p$, at the stage of the defect process Dimension

Based on the above data, it appears that the process is in an uncontrolled control. Some data that is number 5.12, 14,18 are out of control. Average percentage of rejection is 0.00549 with upper control limit of 0.00886 and lower control limit of 0.00213 . Management can perform an indepth analysis of the process, due to the high variability of the product. Analysis can be done on the machine, labor, methods and also the environment that gives an opportunity out of control.

\section{The Influence of Inclusion Insufficiency of (IT) to Dimensions $(D)$}

What is the relationship between the incapacity of inclusion of slag (IT) to the dimension (D). Based on the results of data processing using Pearson analysis gained the relationship is 0.987 or very closely. This means that the occurrence of dimensional disability is closely related to the 
disability occurring in sand inclusions. While the effect of sand inclusion on dimensional disability is $97 \%$.

\section{Correlations}

\begin{tabular}{|ll|c|c|}
\hline & IT & D \\
\hline IT $\quad$ Pearson Correlation & 1 & $.987^{* *}$ \\
& Sig. (2-tailed) & & .000 \\
$\mathrm{~N}$ & 24 & 24 \\
\hline D & $\begin{array}{l}\text { Pearson Correlation } \\
\text { Sig. (2-tailed) }\end{array}$ & $.987^{* *}$ & 1 \\
$\mathrm{~N}$ & .000 & \\
\hline
\end{tabular}

\section{Air Cavity Disability Analysis (RU)}

From the control chart $\mathrm{p}$ in Figure 4, it appears that the number of data is beyond the control limits of numbers 4,5 , 15, 19 and 20. The lower control limit is 0.00057 and the upper control limit is 0.000564 , with the centerline of 0.0031 . The control chart $\mathrm{p}$ that occurs on the air cavity shows an uncontrolled process which indicates the existence of data outside the control limit.

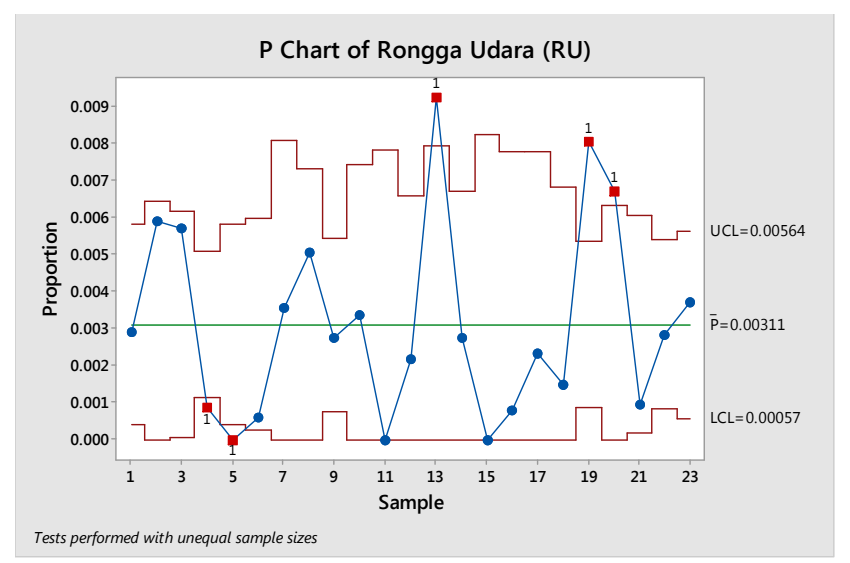

Figure 4: The control chart p, at the stage of the defect process Air Cavity (RU).

\section{O. Influence of Dimensional Density (D) on Air Cavity (RU)}

The following data shows a very close relationship between dimensional defects and "air cavity" defects of 0.98 or near perfect. The magnitude of effect of dimensional defect on air cavity is $96 \%$.

\section{Correlations}

\begin{tabular}{|ll|c|c|}
\hline & D & RU \\
\hline D & Pearson Correlation & 1 & $.981^{* *}$ \\
& Sig. (2-tailed) & & .000 \\
N & 24 & 24 \\
\hline RU Pearson Correlation & $.981^{* *}$ & 1 \\
& Sig. (2-tailed) & .000 & \\
N & 24 & 24 \\
\hline$* *$ Correlation is significant at the 0.01 level (2-tailed).
\end{tabular}

\section{P. Analysis of Print Loss Disability (RC)}

The print loss is a defect indicated by a lump on the surface of the product. Based on the control chart $p$, (figure $5)$, there are 7 data out of the control limit. There is a processed system that causes variability. The data in the control limits are in data numbers: 5, 6,10,11,17,19 and 22.

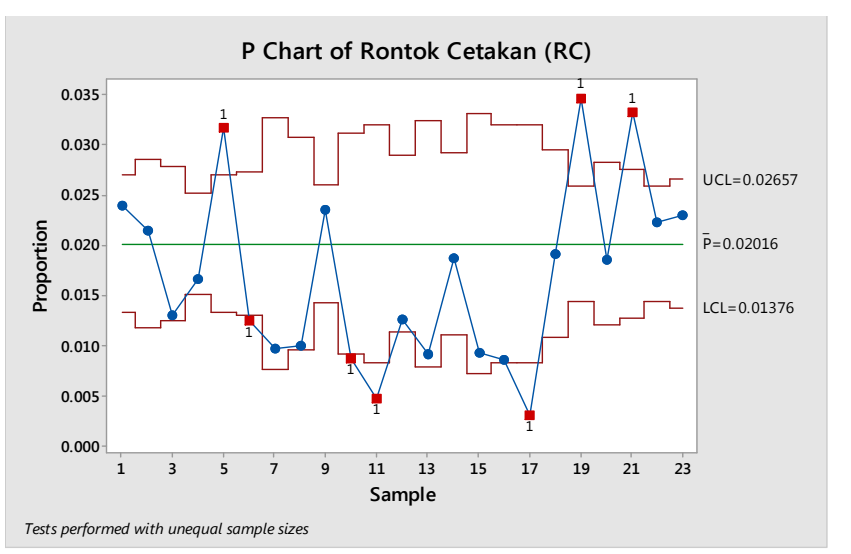

Figure 5: Control chart p, on Mold Loss defects (RU)

\section{Q. Effect of Air Cavity (RU) on Rupok Print (RC)}

The magnitude of the effect of air cavity defects on the defects of cavities is $96.66 \%$. Which is shown with correlation coefficient value of 0.983 .

\section{Correlations}

\begin{tabular}{|cl|c|c|}
\hline & RU & RC \\
\hline RU & Pearson Correlation & 1 & $.983^{* *}$ \\
& Sig. (2-tailed) & & .000 \\
$\mathrm{~N}$ & 24 & 24 \\
\hline RC Pearson Correlation & $.983^{* *}$ & 1 \\
\hline
\end{tabular}




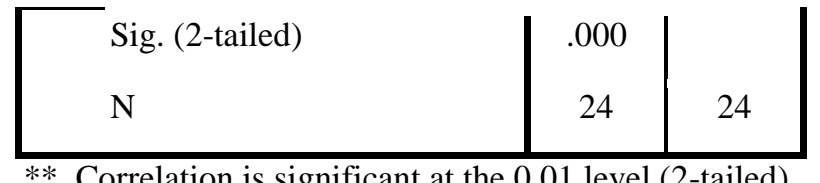

**. Correlation is significant at the 0.01 level (2-tailed).

R. Influence of Inter-Process disability

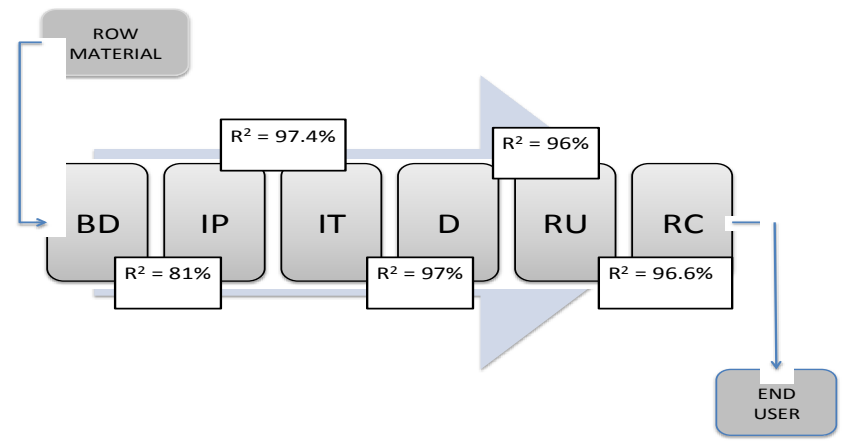

Figure 6: The effect of disability between processes

Of the image, indicating that the defects occurring in the previous process will result in a defect in the next process.

\section{CONCLUSIONS AND SUGGESTIONS}

Based on the results of the analysis shows that all stages of the process in the manufacture of "shoulder" to give an indication of the system is beyond management control, which is shown with data outside the control limit in each stage of the process. Data designated by the control chart, either in the initial defect until the end there is no single control chart under control, this condition indicates poor quality control in the company.

While the results of regeresi and correlation shows the magnitude of the relationship between processes in the cause of disability, even some data show perfection, almost reaching value 1 .

Control must be done since the initial stage of the process, the company must be "brave" when the initial stages of disability must be stopped to be excluded into the next stage.

Of the problems suggested the company to focus more on analyzing the causes of the occurrence of disability is very large both at each stage of the process and in every factor causing the defect. Some things that should be suspected as factors causing disability include machinery, human, raw materials and process handlers are "left" without strict inspection.

\section{References}

[1] B.P. Mahesh, M.S Prabhuswamy (2010) Process Variability Reduction Through Staitistical Process Control For

[2] Qualiy Improvement, International Journal For Quality Research. Vol 4, No 3.

[3] Crosby, P.B, (1986), Quality is Free, The Art Of making Quality Certain, New York, -McGraw-Hill Book Co

[4] Deming W.Edwards, (1986), Out Of The Crisis, Cambridge University Press

[5] Dulce María Rábago-Remy, Edith Padilla-Gasca and Jesús Gabriel Rangel-Peraza (2014). Statistical Quality Control and Process Capability Analysis for Variability Reduction of the Tomato Paste Filling Process. Industrial Engineering \& Management. Volume 3., Issue 4

[6] Grant, E.L. (1993). Statistical Quality Control. McGraw-Hill Book Company, Inc., New York; 1993.

[7] Goetsch, L. D., \& Davis, B. S. (2002). Quality management for produc- tion, processing and services. New Jersey: Prentice-Hall.

[8] Goetsch Davis ( 2014). Quality Management for Organizational Excellence : Introduction to Total Quality. Pearson Educational Limited.36-51

[9] Juran, J. M. (1995). Quality designing, creating the new definition of quali- ty into goods and services. Jakarta: Library Binaman Pressindo.

[10] Juran (2015). Juran's Quality Management and Analysis. Mc Graw Hill International Edition. Singapore.5- 19

[11] Juran M. Joseph (1989), Juran on Quality By Design, New York, McMillan Company

[12] Muwafaq Alkubaisin (2013) “Statistical Quality Control (SQC) and Six Sigma Methodology: An Application of X-Bar Chart on Kuwait Petroleum Company "International Journal of Business Administration. Vol. 4, No 3.

[13] Sugiyono. (2008). Metode Penelitian Kualitatif dan Kuantittaif.Alfabeta.Jakarta.3-17.

[14] Shigeru Mizuno., 1994. Wide Total Quality Control. Jakarta. Management Institute

[15] Tejaningrum. (2016) Mapping the Supply Chain Issues SMEs and Impact for Quality Products. Management Studies Journal, Januari 2016, Vol. 4, No. 1

[16] Tejaningrum.A. (2013). The effectiveness The Supply Chain of soy chips industry. National Conference Entreprneur and Management. Maranatha University. Bandung Indonesia.

[17] Tejaningrum . A. (2014) Inconsistency Quality Products (on Six Sigma Programs) Effect on Customer Loyality: Case Study of Industry "Tahu". Journal "Management Study" ISSN 2328-2185, January 2014. Vol 2 No 1. David Publishing USA.

[18] Tejaningrum.A.,Anton Azis.,Irjayanti (2015). Quality Culture for SMEs Model. Procceding Internatioanl 
Conference Actual Economic, Local Solution For Global Challenges. 2 sd 3 July 2015. Pattaya Thailand.

[19] Tejaningrum.,Mulyono.,Irjayanti (2015) . Measurement Quality Culture. Procceding Internatioan

[20] Tejaningrum . A. (2014a) Inconsistency Quality Products (on Six Sigma Programs) Effect on Customer Loyality: Case Study of Industry "Tahu". Journal "Management Study" ISSN 2328-2185, January 2014. Vol 2 No 1. David Publishing USA.

[21] Tejaningrum.A. (2014b) Analysis of Variance Quality Culture on a Difference Scale Production. International Conference Procceding of ICEHM. 3031 January, Pattaya Thailand.

[22] Tejaningrum, A. (2012). Inkonsistensi Dimensi Kulitas Industri Kreatif UMKM Kota Cimahi dalam Mencapai Nilai Six Sigma. Proccedings from Seminar Nasioanl Kewirausahaan dan Industri Kreatif Bisnis II. SNKIB II Universitas Tarumanegara.

[23] Tejaningrum. A. (2013). Effect of creativity and innovation prodution on performance of Organization (Case study of Industrial wood craft). Proceedings from 3rd International Conference on Management. Penang Malaysia

[24] Oakland, J.S. (1989), Total Quality Management. London: Heinemann professional Publishing Ltd,

[25] Pande, Neman and Cavanagh. In( 2000). The Six Sigma Way. The McGraw-Hill 